\title{
The Chinese Version of the Behavioral Emotion Regulation Questionnaire: Psychometric Properties Among University Students
}

This article was published in the following Dove Press journal: Neuropsychiatric Disease and Treatment

\author{
Ya Zhao' \\ Peihuan $\mathrm{Li}^{\prime}$ \\ Xiang Wang $\mathbb{D}^{2}$ \\ Luya Kong ${ }^{3}$ \\ Yan $\mathrm{Wu}^{\prime}$ \\ Xinchun Liu' \\ 'Department of Clinical Psychology, \\ Third Xiangya Hospital of Central South \\ University, Changsha, People's Republic \\ of China; ${ }^{2}$ Medical Psychological Center, \\ The Second Xiangya Hospital, Central \\ South University, Changsha, People's \\ Republic of China; ${ }^{3}$ School of Public \\ Health, Changsha Medical University, \\ Changsha, People's Republic of China
}

Correspondence: Xinchun Liu Department of Clinical Psychology, Third Xiangya Hospital of Central South University, 138 Tongzipo Road, Yuelu

District, Changsha, Hunan 4I00I3,

People's Republic of China

Tel +86-73|-886-|86-67

Fax +86-73I-888-619-10

Email angelaliu23@sina.com
Background/Purpose: Maladaptive emotion regulation is a strong predictor of depression or anxiety. Behavioral emotion regulation has a direct influence on coping with negative emotion. Although it is interesting to explore more about the behavioral emotion regulation, most of the existing measures can not assess it separately. The Behavioral Emotion Regulation Questionnaire (BERQ) has made important gain in addressing conceptual confusion between cognitive and behavioral emotion regulation. As there is a lack of single and stable measure to assess behavioral emotion regulation in mainland China, we translated the BERQ into Chinese to fit this gap.

Methods: We evaluated the psychometric properties of the Chinese version of the BERQ (BERQ-C) based on a sample of Chinese university students $(n=816)$. Factor analysis was performed to assess the construct validity of the BERQ-C. To test its reliability and validity, all the participants were invited to complete BERQ-C, GAD-7, PHQ-9, and CERQ-C. Of the initial samples, 138 students participated in the second measurement with completing BERQ-C twice.

Results: Confirmatory factor analysis supported the five-factor model. The internal consistence (Cronbach's $\alpha=0.71 \sim 0.85$ ), the split-half reliability (Spearman-Brown coefficient $=$ $0.66 \sim 0.85)$, and the test-retest stability (ICC $=0.55 \sim 0.67)$ are all acceptable. The criterion-related validity is good.

Conclusion: The BERQ-C is a promising instrument to assess behavioral emotion regulation among the Chinese university students. Future studies are needed to explore the questionnaire's psychometric properties among wider range of population especially for patients.

Keywords: emotion regulation, coping, assessment, Chinese university students

\section{Introduction}

Emotion regulation is the processes by individuals influence which the emotions they have, including how they experience and express them. ${ }^{1}$ The concept of emotion regulation can encompass a wider range of implicit cognitive processes (e.g.re-appraise and rumination) and explicit behavioral processes (eg, seeking support and taking action). ${ }^{2}$ Research on emotion regulation focuses on coping. Emotion regulation itself does not have the particularity of the situation but coping refers to the individual's emotional regulation under stress. Negative emotion is the main content of emotion regulation because of its clinical significance. They have different theoretical backgrounds, but they overlap greatly in content, so it is generally believed that coping and emotion regulation are two 
interchangeable concepts. The widely accepted definitions of coping were given by Folkman \& Lazarus (1984; p.14) as "individuals manage specific external and/or internal demands exceeding their own resources through constantly cognitive and behavioral efforts" and by Compas et al $(2001 ;$ p.89) as "in response to stressful event, individuals make volitional efforts to regulate their emotion, cognition, and behavior". 3,4 According to these definitions, an important feature is that they both highlight cognition and behavior as two different processes of emotion regulation responding to stress.

Emotion regulation or coping plays a vital role in managing mental health problems. Previous study has found a correlation between high levels of emotional regulation deficits and increased symptoms of either depression or anxiety. ${ }^{5}$ Research suggests that emotion focused coping was a predictor of depression or anxiety. ${ }^{6,7}$ The recent studies demonstrated that the more frequent use of maladaptive strategies, the more depressive symptoms were observed; however, targeting the ability to regulate emotion may be an effective strategy to reduce the incidence of affective disorders. ${ }^{8,9}$

In view of the important role of emotion regulation in mental health problems, it is necessary to have an effective way to evaluate this psychological structure. Self-report scales are the most common approach. Widely applied psychometric measures include: (a) the Emotion Regulation Questionnaire (ERQ: Gross \& John, 1998) that assesses individual differences in cognitive reappraisal and expression suppression; ${ }^{10}$ (b) the Trait Meta-Mood Scale (TMMS: Salovey \& Mayer, 1990) that explores individual differences in maintaining positive emotions and repairing negative emotions; ${ }^{11}$ (c) the Difficulties in Emotion Regulation Scale (DERS: Gratz \& Roemer, 2004) that examines individuals' difficulty in regulating their emotions; ${ }^{12}$ and (d) coping style questionnaires (ie, the Ways of Coping Questionnaire, Coping Inventory for Stressful Situation, and Coping Inventory) that measure individuals' coping style under stress. ${ }^{13-17}$ However, these widely used measures still have several limitations such as cognition and behavior appear in the same dimension. As cognition and behavior are two different mechanisms at different points in time, it is not appropriate to put these items in the same dimension. ${ }^{2}$ The above measurements fail to assess cognitive and behavioral emotion regulation separately.

The central function of the emotions system is to trigger and organize behavior. ${ }^{18}$ The behavioral emotion regulation has a direct influence on negative emotion (ie, shouting and crying). Although it is interesting to explore more about the behavioral emotion regulation, most of the existing measures cannot assess it accurately. In China, the measurement of emotion regulation is mainly focus on cognition. For example, the Cognitive Emotion Regulation Questionnaire has been translated and validated by Zhu et al. ${ }^{19}$ It indicated that the Chinese version of the Cognitive Emotion Regulation Questionnaire (CERQ-C) is a reliable measure of cognitive emotion regulation strategies and has been widely used in clinical practice. ${ }^{19-22}$ Most of Chinese researchers use the Coping Styles Questionnaire and Simplified Coping Style Questionnaire to evaluate emotional regulation strategies. ${ }^{23-25}$ The above questionnaires are biased towards trait-orientation and ignore the situational particularity of coping. Nevertheless, as the questionnaires contain multiple dimensions, it's hard to distinguish cognition from behavior. Some scholars suggest that the premise of effective assessment is to choose a single, stable measurement tool. ${ }^{26}$ We can see that China's research on the assessment of coping is still insufficient.

The disadvantages mentioned above, especially the confusion of concepts, might reduce the application value of existing measures. It is essential to develop a measure of behavioral emotion regulation with satisfactory psychometric properties. The Behavioral Emotion Regulation Questionnaire (BERQ) was originally developed to assess individual's behavioral strategies of responding to stress by Kraaij and Garnefski using a sample of 457 adults in the Netherlands. ${ }^{27}$ The BERQ is a self-report questionnaire including five conceptually distinct scales. It has shown good psychometric properties. ${ }^{27,28}$ In terms of the criterion-related validity, several BERQ sub-scales have been found to be strongly correlated with the symptoms of depression and anxiety. There was a moderate to strong positive correlation between Withdrawal and depressive symptoms. ${ }^{27}$ It indicated that the higher use of functional behavioral coping strategies may lead to greater mental health. ${ }^{28}$ So far, the Turkish version of the BERQ has been verified in university students as a reliable and valid measure of behavioral emotion regulation. ${ }^{29}$

At present, there is a lack of measures in mainland China that examines the behavioral dimension of emotion regulation. The objectives of this study are therefore: (i) to introduce Behavioral Emotion Regulation Questionnaire (BERQ) into China, (ii) to establish the Chinese version of the Behavioral Emotion Regulation Questionnaire 
(BERQ-C), and (iii) to test its psychometric properties under the Chinese context.

\section{Methods}

\section{Participants}

Participants in the present study were recruited from two universities in Changsha, Hunan (China). A total of 956 freshmen and sophomores from 13 classes participated the first round of assessment. After excluding 140 invalid questionnaires with missing data, we obtained 816 valid questionnaires with $85.40 \%$ effective return ratio. Of the 816 university students $(38.6 \%$ are male and $61.4 \%$ are female). Participants' mean age is 18.54 years (range from 17 to $21 ; \mathrm{SD}=0.78$ ). Among the 816 students, 138 were randomly selected to complete in the second measurement to evaluate test-retest reliability. The research protocol was approved by the local ethics committee. The study was conducted in accordance with the Declaration of Helsinki.

\section{Procedure}

Prior to the preliminary evaluation, written informed consents with detailed explanation of the study were obtained from the participating students. In the first assessment, they completed a demographics questionnaire, the Chinese version of the BERQ (BERQ-C), the Generalized Anxiety Disorder-7 Questionnaire (GAD-7), the Patient Health Questionnaire-9 (PHQ-9) and the Chinese version of the CERQ (CERQ-C). ${ }^{19,30,31}$

To evaluate the test-retest reliability, 138 students completed the BERQ-C two weeks later.

\section{Measures}

\section{The Chinese Version of the Behavioral Emotion Regulation Questionnaire (BERQ-C)}

The Behavioral Emotion Regulation Questionnaire (BERQ) was designed to evaluate individuals' behavioral tendencies in response to stressful events. ${ }^{27}$ This is the simple instruction of BERQ: "By the following questions you are asked to indicate what you generally do, when you experience negative or unpleasant events". The BERQ includes five conceptually distinct scales: (1) Seeking Distraction; (2) Withdrawal; (3) Actively Approaching; (4) Seeking Social Support; (5) Ignoring. These subscales represent the main behavioral styles of coping with stressful events. Each sub-scale consists of four items using five-point Likert scale ranging from 1 ("almost never") to 5 ("almost always"). The total sub-scale score is calculated by summing up the item scores in each scale with a lowest score of 4 and a highest score of 20. It is important to note that higher scores on sub-scales represent a propensity to use that strategy.

The BERQ-C was obtained using the back-translation method. First, with the permission of the BERQ's authors, two bilingual psychological researchers translated the original version into Chinese. The two psychological professors then examined the face validity and checked whether each item was culturally appropriate and comprehensible for the Chinese population. Next, another bilingual translator without knowing the original version from the Psychology Department at Bryn Mawr College translated the Chinese version into English. Finally, the authors of the BERQ reviewed and modified the back-translation to make sure it expresses the accurate meaning. After conducting a pilot test, participants reported no misunderstanding of Chinese version. In this study, the Cronbach's alphas for BERQ-C sub-scales were from moderate to strong with ranging from 0.71 to 0.85 .

\section{Generalized Anxiety Disorder-7 Questionnaire (GAD-7)}

Generalized Anxiety Disorder-7 Questionnaire (GAD-7) was designed to assess the level of generalized anxiety disorders, consisting of 7 items with a four-point Likert scale from 0 ("not at all") to 3 ("nearly every day"). ${ }^{30}$ By summing the items, the total score can be obtained with ranging from 0 to 21 . Scores of 5-9 are mild, $10-14$ is moderate, and $\geqq 15$ is severe anxiety. The higher score reflects greater anxious symptoms. Initial and subsequent studies demonstrated that the GAD-7 is a valid measure to assess anxious symptoms, and the Chinese version of GAD-7 shows good psychometric properties with the Cronbach's alpha was 0.90 and the test-retest reliability was $0.86 .^{30,32}$ In this study, the Cronbach's alpha for CAD-7 $(\alpha=0.87)$ indicated excellent internal consistency, the severity of anxiety was assessed by the Chinese version of GAD-7 to evaluate criterion-related validity.

\section{Patient Health Questionnaire-9 (PHQ-9)}

The severity of depression was assessed with the Patient Health Questionnaire-9 (PHQ-9), consisting of 9 items with the same four-point Likert scale from 0 ("not at all") to 3 ("nearly every day"). ${ }^{31}$ By summing the items, the total score can be obtained with ranging from 0 to 27 with scores of 5-9 indicating mild, 10-14 suggesting moderate, $15-19$ being moderately severe, and $\geqq 20$ 
showing severe depression. The higher scores indicate greater depressive symptoms. In the previous studies, PHQ-9 has been demonstrated as a reliable measurement with the high internal consistency (Cronbach's alpha between 0.86 and 0.89 ) and test-retest reliability (ICC between 0.84 and 0.95$){ }^{33,34}$ The Chinese version of PHQ-9 had good psychometric properties with the Cronbach's alpha being 0.86 and the test-retest reliability being $0.86 .^{35}$ In this study, the Cronbach's alpha for PHQ$9(\alpha=0.80)$ indicated excellent internal consistency, and the severity of depression was used by the Chinese version of PHQ-9 to evaluate criterion-related validity.

\section{The Chinese Version of Cognitive Emotion Regulation Questionnaire (CERQ-C)}

The Cognitive Emotion Regulation (CERQ) was developed to evaluate how people tend to consider under stress. $^{2}$ The Chinese version of CERQ is a reliable measurement to assess cognitive coping strategies, consisting of 9 sub-scales with 4 items each and the five-point Likert scale ranging from 1 (almost never) to 5 (almost always) (Cronbach's alpha between 0.76 and 0.90). ${ }^{19}$ By summing the items, scores on each sub-scale can be obtained with ranging from 4 to 20 . Higher scores on sub-scales indicate a propensity to use that strategy responding to stress. In this study, the Cronbach's alpha for the sub-scales was good with ranging from 0.62 to 0.89 , and we use the CERQ-C to further demonstrate that cognitive and behavioral emotional regulation should be a weak to moderate correlation, and we assumed that they are related but distinct mechanism.

\section{Data Analysis}

All data were collected using a paper form of questionnaires. To test the homogeneity of sub-scales, item analysis and discrimination of items were used. We conducted the confirmatory factor analysis (CFA) to test whether the original factor structure fits the Chinese sample. Multiple indices to examine the reliability were conducted (ie, Cronbach's alpha coefficient that assessing internal consistency, including the equal-length Spearman-Brown coefficient that evaluates split-half reliability, and the Intraclass Correlation Coefficient (ICC) that assesses testretest reliability). The means and standard deviations of BERQ-C sub-scales were calculated. A one-way multivariate analysis of variance (MANOVA) was computed to further explore the effects of sex. The Pearson's correlations among the BERQ-C sub-scales were calculated to support the factorial validity. Pearson's and partial correlation coefficients between the BERQ-C sub-scales and symptoms of depression and anxiety were calculated to evaluate the criterion-related validity. For further exploration of the relationship between cognitive and behavioral emotion regulation, Pearson's correlations between the BERQ-C sub-scales and CERQ-C sub-scales were calculated.

\section{Results Item Analysis}

Prior to the statistical analysis, we carried out the normality test on the data. It suggested that each item's distribution shows normality with the acceptable coefficients of skewness and kurtosis. ${ }^{36}$ Item analysis was calculated to examine the BERQ-C's homogeneity. The result indicated that the item-total correlations of each sub-scales were above the recommended cut-off value of 0.3 with values ranging from 0.63 to $0.88 .{ }^{37}$ Ranking the BERQ-C total score of sub-scales in an ascending order, the score of the top $27 \%$ was significantly lower than the score of the lowest $27 \%$ in each item $(\mathrm{p}<0.001)$.

\section{Factor Structure}

Whether the original five-factor model fitted the Chinese population was tested by confirmatory factor analysis (CFA) using Mplus 8.0 with maximum likelihood estimation (MLM). In fact, for examining factor structure, CFA is more stringent than exploratory factor analysis (EFA) because the former provides for test significance and multiple indices showing good fit. As shown in Table 1, the factor loading of each item was above the 0.4 cut-off criterion with ranging from acceptable to good. ${ }^{38}$

Since Chi-square is easily affected by sample size, four other indices were analyzed (values in parentheses denote goodness-of-fit standards proposed by $\mathrm{Hu}$ and Bentler) in Table 2: (1) the comparative fit index (CFI $>0.90)$; (2) the Tucker-Lewis index (TLI $>0.90)$; (3) the root means square error of approximation (RMSEA $\leqq 0.08$ ); and (4) the standardized root mean square residual (SRMR $\leqq 0.08) .{ }^{39,40}$

\section{Reliability}

Based on the literature, if Cronbach's alpha coefficient is below 0.6 or 0.5 , it is regarded as unacceptable. ${ }^{41}$ As shown in Table 3, the Cronbach's alpha for the BERQ-C ranged from 0.71 (Actively Approaching) to 0.85 (Withdrawal). The equal-length Spearman-Brown coefficient 
Table I Factor Loadings of the BERQ-C in CFA $(n=8 \mid 6)$

\begin{tabular}{|l|l|l|}
\hline Latent Factors & Items & $\begin{array}{l}\text { Standardized } \\
\text { Factor Loading } \\
\text { Coefficients }\end{array}$ \\
\hline Factor I & 1 & 0.427 \\
& 16 & 0.565 \\
& 11 & 0.803 \\
& 6 & 0.741 \\
\hline Factor 2 & 2 & 0.575 \\
& 17 & 0.853 \\
& 12 & 0.880 \\
\hline Factor 3 & 7 & 0.756 \\
\hline Factor 4 & 3 & 0.424 \\
& 18 & 0.725 \\
& 13 & 0.830 \\
& 8 & 0.518 \\
\hline Factor 5 & 4 & 0.653 \\
& 19 & 0.769 \\
& 14 & 0.797 \\
& 9 & 0.788 \\
\hline & 5 & 0.577 \\
& 20 & 0.703 \\
& 15 & 0.698 \\
& 10 & 0.804 \\
\hline
\end{tabular}

Table 2 Fit Indices of Measurement Invariant $(n=816)$

\begin{tabular}{|l|l|l|l|l|l|l|}
\hline Model & S-B $\chi^{2}$ & df & CFI & TLI & $\begin{array}{l}\text { RMSEA } \\
(\mathbf{9 0 \%} \mathbf{~ C l})\end{array}$ & SRMR \\
\hline $\begin{array}{l}\text { Five- } \\
\text { factor } \\
\text { model }\end{array}$ & 469.111 & 160 & 0.937 & 0.925 & $\begin{array}{l}0.049 \\
(0.044-0.054)\end{array}$ & 0.052 \\
\hline
\end{tabular}

Abbreviations: df, degree of freedom; CFl, comparative fit index; TLI, TuckerLewis index; RMSEA, root means square error of approximation; SRMR, standardized root mean square residual.

ranged from 0.66 (Actively Approaching) to 0.85 (Seeking Distraction). The ICC between sub-scale scores of the first and second measurement ranged from 0.55 to 0.67 . ICC was considered to be more suitable than Pearson's correlation coefficient. $^{42}$ Taking into account of the recommendation a precious study, an ICC that falls into the categories of $0.10,0.11-0.40,0.40-0.60,0.61-0.80$, and $>0.80$, was considered to be no consistency, poor, ordinary, moderate, and good, respectively. ${ }^{43}$

\section{BERQ-C Means and Standard Deviations}

As shown in Table 4, the mean of Seeking Distraction, Actively Approaching and Seeking Social Support was
Table 3 BERQ-C reliability: Internal Consistency, Split-Half Reliability, and Test-Retest Reliability

\begin{tabular}{|l|l|l|l|}
\hline BERQ-C Sub-Scales & $\begin{array}{l}\text { Cronbach' } \\
\text { Alpha } \mathbf{( n =} \\
\mathbf{8 I 6 )}\end{array}$ & $\begin{array}{l}\text { Spearman- } \\
\text { Brown } \\
\text { Coefficient } \\
(\mathbf{n = 8 1 6 )}\end{array}$ & $\begin{array}{l}\text { Intraclass } \\
\text { Correlation } \\
\text { Coefficient } \\
(\mathbf{n}=138)\end{array}$ \\
\hline Seeking Distraction & 0.72 & 0.72 & $0.58^{* * *}$ \\
Withdrawal & 0.85 & 0.82 & $0.64^{* * *}$ \\
Actively Approaching & 0.71 & 0.66 & $0.55^{* * *}$ \\
Seeking Social Support & 0.84 & 0.85 & $0.67^{* * *}$ \\
Ignoring & 0.79 & 0.76 & $0.6 I^{* * *}$ \\
\hline
\end{tabular}

Note: $* * * p<0.001$.

13.52, whereas the mean of Withdrawal and Ignoring was 9.05. Seeking Distraction's mean score is the highest, and Withdrawal's mean score is the lowest. A one-way MANOVA result suggested that the scores of Withdrawal $(\mathrm{F}=14.14, \mathrm{P}<0.01)$ and Seeking Social support $(\mathrm{F}=11.46$, $\mathrm{P}<0.01$ ) had significant sex differences. Females (means are 9.25 and 13.72 accordingly) scored higher on Withdrawal and Seeking Social Support than males (means are 8.45 and 13.01 accordingly). The other sub-scales have no statistically significant sex differences $(\mathrm{P}>0.01)$.

\section{Correlations Between the BERQ-C Sub-Scales}

As shown in Table 5, correlations for the BERQ-C ranged from 0.09 (Seeking Distraction and Actively Approaching) to 0.64 (Withdrawal and Ignoring).

\section{Criterion-Related Validity}

As shown in Table 6, Pearson's correlations between the BERQ-C sub-scales and depressive symptoms ranged from -0.13 (Seeking Distraction) to 0.42 (Withdrawal). All BERQ-C sub-scales significantly correlated with depressive symptoms. After controlling for the interaction between sub-scales (Partial correlations), Actively Approaching and Seeking Social Support did not significantly correlated with depressive symptoms.

Pearson's correlations between the BERQ-C sub-scales and anxious symptoms ranged from -0.20 (Actively Approaching) to 0.41 (Withdrawal). After controlling for the interaction (Partial correlations), Seeking Distraction, Actively Approaching, Seeking Social Support and Ignoring did not significantly correlated with anxious symptoms. However, withdrawal had significantly positive correlation with anxious symptoms. 
Table 4 BERQ-C Means and Standard Deviations

\begin{tabular}{|c|c|c|c|c|c|c|}
\hline $\begin{array}{l}\text { BERQ-C Sub- } \\
\text { Scales }\end{array}$ & $\begin{array}{l}\text { Total Participants } \\
(n=816) \text { Mean } \pm S D\end{array}$ & $\begin{array}{l}\text { Male Participants } \\
(n=3 \text { I5) Mean } \pm S D\end{array}$ & $\begin{array}{l}\text { Female Participants } \\
(n=50 \text { I) Mean } \pm S D\end{array}$ & F-Test & $\mathbf{p}$ & $\begin{array}{l}\text { Cohen's } \\
\text { d }\end{array}$ \\
\hline Seeking Distraction & $13.67 \pm 2.34$ & $13.52 \pm 2.37$ & $|3.77 \pm 2.3|$ & 2.18 & 0.14 & 0.003 \\
\hline Withdrawal & $8.94 \pm 3.00$ & $8.45 \pm 2.99$ & $9.25 \pm 2.96$ & 14.14 & 0.0001 & 0.017 \\
\hline Actively Approaching & $13.45 \pm 2.26$ & $13.67 \pm 2.43$ & $|3.3| \pm 2.14$ & 4.93 & 0.03 & 0.006 \\
\hline Seeking Social Support & $|3.44 \pm 2.9|$ & $13.01 \pm 2.93$ & $13.72 \pm 2.87$ & 11.46 & 0.0001 & 0.014 \\
\hline Ignoring & $9.15 \pm 0.90$ & $9.04 \pm 2.89$ & $9.15 \pm 2.90$ & 0.70 & 0.40 & 0.001 \\
\hline
\end{tabular}

Table 5 Pearson's Correlations Between BERQ-C Sub-Scales $(n=8 \mid 6)$

\begin{tabular}{|l|l|l|l|l|}
\hline BERQ-C Sub-Scales & $\mathbf{I}$ & $\mathbf{2}$ & $\mathbf{3}$ & $\mathbf{4}$ \\
\hline I. Seeking Distraction & - & & & \\
2. Withdrawal & -0.05 & - & & \\
3. Actively Approaching & $0.09^{* *}$ & $-0.27^{* *}$ & - & \\
4. Seeking Social Support & $0.22^{* *}$ & $-0.26^{* *}$ & $0.28^{* *}$ & - \\
5. Ignoring & 0.03 & $0.64^{* *}$ & $-0.24^{* *}$ & $-0.29 * *$ \\
\hline
\end{tabular}

Note: $* * p<0.01$.

Table 6 Pearson's and Partial Correlations Between the BERQC Sub-Scales and Symptoms of Depression and Anxiety

\begin{tabular}{|c|c|c|c|c|}
\hline \multirow[t]{2}{*}{$\begin{array}{l}\text { BERQ-C Sub- } \\
\text { Scales }\end{array}$} & \multicolumn{2}{|c|}{$\begin{array}{l}\text { Depressive } \\
\text { Symptoms }(n= \\
816)\end{array}$} & \multicolumn{2}{|c|}{$\begin{array}{l}\text { Anxious } \\
\text { Symptoms } \\
(n=8 \mid 6)\end{array}$} \\
\hline & $\begin{array}{l}\text { Pearson } \\
r\end{array}$ & $\begin{array}{l}\text { Partial } \\
r\end{array}$ & $\begin{array}{l}\text { Pearson } \\
r\end{array}$ & $\begin{array}{l}\text { Partial } \\
\mathbf{r}\end{array}$ \\
\hline Seeking Distraction & $-0.13^{* *}$ & $-0.13 * * *$ & -0.03 & -0.03 \\
\hline Withdrawal & $0.42 * *$ & $0.26^{* * *}$ & $0.41^{* * * *}$ & $0.30^{* * *}$ \\
\hline $\begin{array}{l}\text { Actively } \\
\text { Approaching }\end{array}$ & $-0.19 * *$ & -0.07 & $-0.20 * *$ & -0.02 \\
\hline $\begin{array}{l}\text { Seeking Social } \\
\text { Support }\end{array}$ & $-0.14 * *$ & 0.03 & -0.05 & 0.08 \\
\hline Ignoring & $0.34 * *$ & $0.11 * *$ & $0.30 * * *$ & 0.07 \\
\hline
\end{tabular}

Note: $*^{*} \mathrm{p}<0.01, *^{* *} \mathrm{p}<0.001$.

\section{Correlations Between BERQ-C and CERQ-C Sub-Scales}

As shown in Table 7, Pearson's correlations between the BERQ-C sub-scales and CERQ-C sub-scales ranged from 0.09 to 0.61 . Additionally, there were some weak significant correlations and 4 moderate to strong significant correlations: Withdrawal $(\mathrm{r}=0.61)$ /gnoring $(\mathrm{r}=0.61)$ and Rumination had the strong correlations, and Actively Approaching had moderate correlations with Refocus on Planning $(\mathrm{r}=0.43) /$ Positive Reappraisal $(\mathrm{r}=0.43)$.

\section{Discussion}

The aim of the present study was to evaluate the psychometric properties of the BERQ-C for providing a better instrument to measure the behavioral coping strategies of responding to stress. At first, item analysis showed appropriate homogeneity of each sub-scale. The CFA confirmed that the BERQ-C had five factors: Seeking Distraction (items 1, 6, 11, 16); Withdrawal (items 2, 7, 12, 17); Actively Approaching (items 3, 8, 13, 18); Seeking Social Support (items 4, 9, 14, 19) and Ignoring (items $5,10,15,20)$. It was in line with the original version and Turkish version. ${ }^{27,29}$

More specifically, the results suggest that the BERQ-C is a reliable measure. The Cronbach' alpha coefficients were greater than 0.70 with good internal homogeneity. ${ }^{44}$

The Turkish version of the BERQ $(\alpha=0.72$ to 0.88$)$ may possess slightly stronger internal consistency than the BERQ-C ( $\alpha=0.72$ to 0.85$)$. The split-half reliability was acceptable, and test-retest reliability was from ordinary to moderate, indicating that the BERQ-C is a relatively stable measurement. Although the test-retest reliability obtained in the current study (mean $\mathrm{ICC}=0.61$ ) were slightly higher than those obtained by Tuna (mean ICC $=0.60$ ), this is possibly due to the test-retest interval used in the current study ( 2 weeks) being shorter than that used by Tuna' study ( 3 weeks). ${ }^{29}$

Moreover, according to the means and standards deviations of the BERQ-C sub-scales, the Seeking Distraction, Actively Approaching and Seeking Social Support (mean=13.52) were reported to be more common than the Withdrawal and Ignoring (mean=9.05). This finding was consistent with past research examining the Turkish version of the BERQ and a sample of adults from a GP practice. ${ }^{27,29}$ In our opinion, this should be attributed to the sample which included all registered university students and did not consider clinical samples. Referring to the previous literature, the next step should be conducted in clinic to compare the differences in behavioral coping strategies between a clinical population and 
Table 7 Pearson Correlations Between the BERQ-C and CERQ-C $(n=8 \mid 6)$

\begin{tabular}{|c|c|c|c|c|c|c|c|c|c|}
\hline \multirow{2}{*}{$\begin{array}{l}\text { BERQ-C Sub- } \\
\text { Scales }\end{array}$} & \multicolumn{9}{|c|}{ CERQ-C Sub-Scales } \\
\hline & $\begin{array}{l}\text { Self- } \\
\text { Blame }\end{array}$ & Acceptance & Rumination & $\begin{array}{l}\text { Positive } \\
\text { Refocusing }\end{array}$ & $\begin{array}{l}\text { Refocus } \\
\text { on } \\
\text { Planning }\end{array}$ & $\begin{array}{l}\text { Positive } \\
\text { Reappraisal }\end{array}$ & $\begin{array}{l}\text { Putting } \\
\text { into } \\
\text { Perspective }\end{array}$ & Catastrophizing & $\begin{array}{l}\text { Blaming } \\
\text { Others }\end{array}$ \\
\hline Seeking Distraction & $0.10 * *$ & $0.14 * * *$ & $0.41 * * *$ & $0.37 * * *$ & $0.23 * * *$ & $0.22^{* * *}$ & $0.09 *$ & $-0.11^{* *}$ & $-0.09 *$ \\
\hline Withdrawal & $0.16^{* * * *}$ & 0.02 & $0.61^{* * *}$ & $-0.13^{* * *}$ & $-0.15^{* * * *}$ & $-0.20 * * *$ & $0.16^{* * *}$ & $0.34^{* * *}$ & $0.27^{* * *}$ \\
\hline Actively Approaching & $0.16^{* * * *}$ & $0.22 * * *$ & -0.04 & $0.16 * * *$ & $0.43 * * *$ & $0.43^{* * *}$ & 0.06 & $0.12^{* * *}$ & $-0.12^{* *}$ \\
\hline $\begin{array}{l}\text { Seeking Social } \\
\text { Support }\end{array}$ & 0.04 & 0.06 & $0.21 * * *$ & $0.21 * * *$ & $0.26^{* * * *}$ & $0.28^{* * * *}$ & $0.09 *$ & -0.04 & -0.01 \\
\hline Ignoring & $0.14^{* * * *}$ & $0.10 * *$ & $0.61 * * *$ & -0.06 & $-0.16^{* * * *}$ & $-0.17^{* * * *}$ & $0.2^{* * * *}$ & $0.32^{* * * *}$ & $0.30 * * *$ \\
\hline
\end{tabular}

Note: ${ }^{*} p<0.05,{ }^{* *} \mathrm{p}<0.01,{ }^{* * *} \mathrm{p}<0.001$.

the general population. ${ }^{45}$ Females reported a higher mean score on Withdrawal and Seeking Social Support, and it may seem paradoxical. When it comes to the traditional Chinese culture, this finding is interesting to explore. An early study had posited that culture influences the style of coping, and thus further study should test the specific cultural factors influence the choice of coping strategies. ${ }^{46}$ Gender roles in Chinese culture determine that women's emotional expression can easily obtain social support. But for men, emotional expression is less socially acceptable and can be interpreted as an inability to deal with problems. ${ }^{47}$ When individuals are lack of social support, emotional appeal is hindered. Women may be more likely to suspend the processing of negative emotions by avoiding to relieving emotional tension. However, to men, avoidance is not encouraged and they are more likely to relieve emotional stress by solving problems or substance dependence. ${ }^{48}$ Therefore, it is understandable why women scored higher in Seeking Social Support and Withdrawal than men in our study.

Next, there was a correlation from weak to moderate between five sub-scales, and results suggested that the five sub-scales are related but distinct. Further, there was a stronger correlation between the Withdrawal and Ignoring than among the Seeking Distraction, Actively Approaching, and Seeking Social Support. Meanwhile, it is important to point out that the Seeking Distraction, Actively Approaching, and Seeking Social Support had negative correlation with the Withdrawal and Ignoring, indicating that it may be reasonable to consider the function of the coping strategies.

Furthermore, the correlations between the BERQ-C subscales and depressive and anxious symptoms indicated that Withdrawal and Ignoring had a positive correlation with depressive and anxious symptoms. This finding is in line with previous studies. ${ }^{49,50}$ In terms of the strength of the correlations, compared with the Seeking Distraction,
Actively Approaching, and Seeking Social Support, there was a stronger correlation between Withdrawal and Ignoring and psychopathology. According to a metaanalytic review study, the emergence of maladaptive strategies may be more dangerous than the absence of adaptive strategies. ${ }^{51}$ In particular, after controlling for the interrelationships, only the Withdrawal remained significantly positively correlated with anxious symptoms $(\mathrm{r}=0.30)$. This indicates that behavioral models of emotional avoidance may result in increased anxious symptoms by leading to more intrusion of unwanted experiences and physiological arousal. Research on the suppression and avoidance of emotion indicated that on the one hand, emotional avoidance can hinder the learning process and maintain anxious response, on the other hand, it can aggravate anxious responses to threatening cues and further impeding adaptive response. ${ }^{52}$

With respect to the relationship between BERQ-C and CERQ-C sub-scales, there existed from weak to moderate correlation. This is consistent with our hypothesis that they are related but distinct mechanism. The strong correlation between Withdrawal and Rumination $(\mathrm{r}=0.61)$ seems to be justified since individuals both avoid themselves from the present moment and stop contacting with new people or situations. (ie, In a behavioral way, "I close myself off to others". While in a cognitive manner, "I am preoccupied with what I think and feel about what I have experienced".) However, the shared variance (37.21\%) indicates that they are two different processes. The strong correlation between Ignoring and Rumination $(\mathrm{r}=0.61)$ just showed the heterogeneity between cognition and behavior. (ie, In a behavioral way, "I repress it and pretend it never happened". While in a cognitive manner, "I am preoccupied with what I think and feel about what I have experienced".) Attempted suppression has paradoxical effects as a self-control strategy, perhaps even producing 
the very obsession or preoccupation that it is directed against. $^{53}$ Emotional neglect in behavioral dimensions may lead to more cognitive emotional processing. Although the moderate correlations were found for Actively Approaching and Positive Reappraisal/Refocus on Planning, both of their shared variances are only $18 \%$, and they are not the same process. The reason why they had moderate correlation is that they both focus on action (eg, In a behavioral way, "I try to do something about it". While in a cognitive manner, "I think of what I can do best" or "I think I can learn something from the situation".). Generally speaking, behavioral and cognitive emotion regulation strategies are related but have many unique variances.

This study has two main limitations. First, we selected university students as the sample, which may influence the generalizability of the above results. Further studies should continue to test the psychometric properties of the BERQ$\mathrm{C}$ in wider populations including adults and patients. Second, given the nature of the study design as a crosssectional study, we cannot come to a conclusion about the causality. Further research should focus on longitudinal study to determine whether inherit behavioral emotion regulation strategies affect the level of depression and anxiety.

\section{Conclusions}

To conclude, good psychometric properties of the BERQ$\mathrm{C}$ were confirmed in a sample of Chinese university students. Meanwhile, the BERQ-C was easy to understand and implement. Although this study provided preliminary information for the application of the BERQ-C in other populations, there is still a lack of widely used measurement, it needs to be confirmed in different samples, especially in clinical population. The BERQ-C will be an effective measurement to assess behavioral emotion regulation in China.

\section{Ethical Approval}

The Institutional Review Board (IRB) of the Third Xiangya Hospital in Hunan approved the study (2020S344).

\section{Acknowledgments}

We would like to thank Miss. Peihuan Li and Dr Wang for their help in Writing-review and editing, and Mrs. Luya Kong and Mrs. Yan Wu for their help in data collection.

\section{Disclosure}

The authors report no conflicts of interest in this work.

\section{References}

1. Gross JJ. The emerging field of emotion regulation: an integrative review. Rev Gen Psychol. 1998;2(3):271-299. doi:10.1037/10892680.2.3.271

2. Garnefski N, Kraaij V, Spinhoven P. Negative life events, cognitive emotion regulation and emotional problems. Pers Individ Dif. 2001;30(8):1311-1327. doi:10.1016/S0191-8869(00)00113-6

3. Lazarus RS, Folkman S. Stress, Appraisal, and Coping. Springer publishing company; 1984.

4. Compas BE, Connor-Smith JK, Saltzman H, Thomsen AH, Wadsworth ME. Coping with stress during childhood and adolescence: problems, progress, and potential in theory and research. Psychol Bull. 2001;127(1):87. doi:10.1037/0033-2909.127.1.87

5. Auerbach RP, Abela JRZ, Ringo Ho M-H. Responding to symptoms of depression and anxiety: emotion regulation, neuroticism, and engagement in risky behaviors. Behav Res Ther. 2007;45 (9):2182-2191. doi:10.1016/j.brat.2006.11.002

6. Rafnsson FD, Jonsson FH, Windle M. Coping strategies, stressful life events, problem behaviors, and depressed affect. Anxiety Stress Coping. 2006;19(3):241-257. doi:10.1080/10615800600679111

7. Wingo AP, Baldessarini RJ, Windle M. Coping styles: longitudinal development from ages 17 to 33 and associations with psychiatric disorders. Psychiatry Res. 2015;225(3):299-304. doi:10.1016/j. psychres.2014.12.021

8. Stikkelbroek Y, Bodden DH, Kleinjan M, Reijnders M, van Baar AL. Adolescent depression and negative life events, the mediating role of cognitive emotion regulation. PLoS One. 2016;11(8):e0161062. doi:10.1371/journal.pone. 0161062

9. Lopez RB, Denny BT. Negative affect mediates the relationship between use of emotion regulation strategies and general health in college-aged students. Pers Individ Dif. 2019;151:109529. doi:10.1016/j.paid.2019.109529

10. Gross JJ, John OP. Mapping the domain of expressivity: multimethod evidence for a hierarchical model. J Pers Soc Psychol. 1998;74 (1):170. doi:10.1037/0022-3514.74.1.170

11. Salovey P, Mayer JD. Emotional intelligence. Imagin Cogn Pers. 1990;9(3):185-211. doi:10.2190/DUGG-P24E-52WK-6CDG

12. Gratz KL, Roemer L. Multidimensional assessment of emotion regulation and dysregulation: development, factor structure, and initial validation of the difficulties in emotion regulation scale. J Psychopathol Behav Assess. 2004;26(1):41-54. doi:10.1023/B: JOBA.0000007455.08539.94

13. Folkman S, Lazarus RS, Gruen RJ, DeLongis A. Appraisal, coping, health status, and psychological symptoms. J Pers Soc Psychol. 1986;50(3):571. doi:10.1037/0022-3514.50.3.571

14. Lazarus RS, Folkman S. Transactional theory and research on emotions and coping. Eur J Pers. 1987;1(3):141-169. doi:10.1002/ per.2410010304

15. Endler NS, Parker JD. Multidimensional assessment of coping: a critical evaluation. $J$ Pers Soc Psychol. 1990;58(5):844. doi:10.1037/0022-3514.58.5.844

16. Endler NS, Parker JD. Assessment of multidimensional coping: task, emotion, and avoidance strategies. Psychol Assess. 1994;6(1):50. doi:10.1037/1040-3590.6.1.50

17. Carver CS, Scheier MF, Weintraub JK. Assessing coping strategies: a theoretically based approach. J Pers Soc Psychol. 1989;56(2):267. doi:10.1037/0022-3514.56.2.267

18. Cicchetti D, Ackerman BP, Izard CE. Emotions and emotion regulation in developmental psychopathology. Dev Psychopathol. 1995;7 (1):1-10. doi:10.1017/S0954579400006301 
19. Zhu X, Auerbach RP, Yao S, et al. Psychometric properties of the cognitive emotion regulation questionnaire: Chinese version. Cogn Emot. 2008;22(2):288-307. doi:10.1080/02699930701369035

20. Xiao J, Yao S, Zhu X, et al. A prospective study of cognitive emotion regulation strategies and depressive symptoms in patients with essential hypertension. Clin Exp Hypertens. 2011;33(1):63-68. doi:10.3109/10641963.2010.531832

21. Lei H, Zhang X, Cai L, Wang Y, Bai M, Zhu X. Cognitive emotion regulation strategies in outpatients with major depressive disorder. Psychiatry Res. 2014;218(1-2):87-92. doi:10.1016/j.psychres.2014. 04.025

22. Wang Y, Yi J, He J, et al. Cognitive emotion regulation strategies as predictors of depressive symptoms in women newly diagnosed with breast cancer. Psycho-Oncology. 2014;23(1):93-99. doi:10.1002/pon.3376

23. Jiang Q, Zhu Y. Further explorations for a coping style questionnaire. Depart Med Psychol. 1999;8(3):167-169.

24. Xie Y. A preliminary study on the reliability and validity of the simplified coping style questionnaire. Chin J Clin Psychol. 1998;6 (2):114-115.

25. Xiao J, Xu X. Study on the validity and reliability of "coping style questionnaire". Chin Ment Health J. 1996;(04):164-168.

26. Liang B. Positive results, problems and their solutions in coping research. Acta Psychological Sinica. 2002;34(06):91-98.

27. Kraaij V, Garnefski N. The behavioral emotion regulation questionnaire: development, psychometric properties and relationships with emotional problems and the cognitive emotion regulation questionnaire. Pers Individ Dif. 2019;137:56-61. doi:10.1016/j. paid.2018.07.036

28. Lovian D The relationship of cognitive coping, behavioral coping, and religious coping strategies with academic stress, depression, and anxiety in college students in Indonesia. 2019.

29. Tuna E. Psychometric properties of the Turkish version of the behavioral emotion regulation questionnaire (BERQ). J Gen Psychol. 2020;1-17. doi:10.1080/00221309.2020.1752137

30. Spitzer RL, Kroenke K, Williams JB, Löwe B. A brief measure for assessing generalized anxiety disorder: the GAD-7. Arch Intern Med. 2006;166(10):1092-1097. doi:10.1001/archinte.166.10.1092

31. Spitzer RL, Kroenke K, Williams JB. Validation and utility of a self-report version of PRIME-MD: the PHQ primary care study. JAMA. 1999;282(18):1737-1744. doi:10.1001/jama.282.18.1737

32. He X, Li C, Qian J, Cui H, Wu W. Reliability and validity of a generalized anxiety disorder scale in general hospital outpatients. Shanghai Arch Psychiatry. 2010;22(4):200-203.

33. Kroenke K, Spitzer RL, Williams JB. The PHQ-9: validity of a brief depression severity measure. J Gen Intern Med. 2001;16(9):606-613. doi:10.1046/j.1525-1497.2001.016009606.x

34. Löwe B, Spitzer RL, Gräfe K, et al. Comparative validity of three screening questionnaires for DSM-IV depressive disorders and physicians' diagnoses. J Affect Disord. 2004;78(2):131-140. doi:10. 1016/S0165-0327(02)00237-9

35. Wang W, Bian Q, Zhao Y, et al. Reliability and validity of the Chinese version of the patient health questionnaire (PHQ-9) in the general population. Gen Hosp Psychiatry. 2014;36(5):539-544. doi:10.1016/j.genhosppsych.2014.05.021

Neuropsychiatric Disease and Treatment

\section{Publish your work in this journal}

Neuropsychiatric Disease and Treatment is an international, peerreviewed journal of clinical therapeutics and pharmacology focusing on concise rapid reporting of clinical or pre-clinical studies on a range of neuropsychiatric and neurological disorders. This journal is indexed on PubMed Central, the 'PsycINFO' database and CAS, and
36. Curran PJ, West SG, Finch JF. The robustness of test statistics to nonnormality and specification error in confirmatory factor analysis. Psychol Methods. 1996;1(1):16. doi:10.1037/1082-989X.1.1.16

37. Nunnally JC. Psychometric Theory 3E. Tata McGraw-Hill Education; 1994.

38. Tabachnick BG, Fidell LS, Ullman JB. Using Multivariate Statistics. Vol. 5. Boston, MA: Pearson; 2007.

39. van de Schoot R, Lugtig P, Hox J. A checklist for testing measurement invariance. Eur $J$ Dev Psychol. 2012;9(4):486-492. doi:10.1080/17405629.2012.686740

40. $\mathrm{Hu} \mathrm{L}$, Bentler PMJSEM. Cutoff criteria for fit indexes in covariance structure analysis: conventional criteria versus new alternatives. Struct Equ Modeling. 1999;6(1):1-55.

41. Zwaanswijk W, Veen VC, Vedder P. The youth psychopathic traits inventory: a bifactor model, dimensionality, and measurement invariance. Assessment. 2017;24(7):932-944. doi:10.1177/1073191116632340

42. Shrout PE, Fleiss JL. Intraclass correlations: uses in assessing rater reliability. Psychol Bull. 1979;86(2):420-428. doi:10.1037/00332909.86.2.420

43. Shrout PE. Measurement reliability and agreement in psychiatry. Stat Methods Med Res. 1998;7(3):301-317. doi:10.1177/096228029 800700306

44. DeVellis RF. Scale Development: Theory and Applications. Vol. 26. Sage publications; 2016.

45. Garnefski N, Van Den Kommer T, Kraaij V, Teerds J, Legerstee J, Onstein E. The relationship between cognitive emotion regulation strategies and emotional problems: comparison between a clinical and a non-clinical sample. Eur J Pers. 2002;16(5):403-420. doi: $10.1002 /$ per. 458

46. Triandis HC. The psychological measurement of cultural syndromes. Am Psychol. 1996;51(4):407. doi:10.1037/0003-066X.51.4.407

47. Sun YY Research on Emotional approach coping and its application in clinic. Chinese

48. Qi C A pilot study of barriers to drug dependence treatment in China. Chinese

49. Joormann J, Stanton CH. Examining emotion regulation in depression: a review and future directions. Behav Res Ther. 2016;86:35-49. doi:10.1016/j.brat.2016.07.007

50. Kato T. Frequently used coping scales: a meta-analysis. Stress Health. 2015;31(4):315-323. doi:10.1002/smi.2557

51. Aldao A, Nolen-Hoeksema S, Schweizer S. Emotion-regulation strategies across psychopathology: a meta-analytic review. Clin Psychol Rev. 2010;30(2):217-237. doi:10.1016/j.cpr.2009.11.004

52. Salters-Pedneault K, Tull MT, Roemer L. The role of avoidance of emotional material in the anxiety disorders. Appl Prev Psychol. 2004;11(2):95-114. doi:10.1016/j.appsy.2004.09.001

53. Wegner DM, Schneider DJ, Carter SR, et al. Paradoxical effects of thought suppression. J Pers Soc Psychol. 1987;53(1):5-13. doi:10.1037/0022-3514.53.1.5 is the official journal of The International Neuropsychiatric Association (INA). The manuscript management system is completely online and includes a very quick and fair peer-review system, which is all easy to use. Visit http://www.dovepress.com/testimonials.php to read real quotes from published authors. 